\title{
Teaching Magnetic Component Design in Power Electronics Course using Project Based Learning Approach
}

\author{
Alenka Hren*, Miro Milanovic*, and Franc Mihalic ${ }^{\dagger}$ \\ $\dagger^{*}$ Faculty of Electrical Engineering and Computer Science, University of Maribor, Maribor, Slovenia
}

\begin{abstract}
This paper presents the results and gained experiences from the Project Based Learning (PBL) of magnetic component design within a Power Electronics Course. PBL was applied during the laboratory exercises through a design-project task based on a boost converter test board. The students were asked to calculate the main boost converter's circuit parameters' capacitor C and inductor $\mathrm{L}$, and then additionally required to design and build-up the inductor $\mathrm{L}$, in order to meet the project's goals. The whole PBL process relied on ideas from the CDIO (Conceive, Design, Implement, Operate), where the students are encouraged to consider the whole system's process, in order to obtain hands-on experience. PBL is known to be a motivating and problem-centered teaching method that gives students the ability to transfer their acquired scientific knowledge into industrial practice. It has the potential to help students cope with demanding complexities in the field, and those problems they will face in their future careers.
\end{abstract}

Key Words: Electromagnetics, Inductor, Project based learning, Power electronics

\section{INTRODUCTION}

This paper presents the results gained after two years experience of using PBL teaching of electromagnetics, as realized from a student design-project task in power electronics, based on a boost converter test board layout. This test board was used during laboratory exercises as part of an advanced course in Power Electronics, offered as an optional subject to the third year students of a professionally-oriented undergraduate study program. During the second year of their curriculum, the students had participated in a basic course on Industrial Electronics that covered the basics of $\mathrm{dc} / \mathrm{dc}, \mathrm{ac} / \mathrm{dc}$, and $\mathrm{dc} / \mathrm{ac}$ converters. The applied teaching methods in this course followed the strategy described in [1], which used theoretical lectures in conjunction with simulations and measurements in the laboratory. In this advanced course on Power Electronics, however, the converter's design and dynamical analysis are treated, amongst other themes, in combination with theoretical lectures using the PBL approach. One of the goals of the using PBL approach was to make power electronics more attractive to students, especially to those who originally preferred nonpower related subjects.

In general, engineers have to deal with uncertainty, yet solving complex problems, and they need to be able to function

Manuscript received Aug. 4, 2011; revised Nov. 25, 2011

Recommended for publication by Associate Editor Jaeho Choi.

$\dagger$ Corresponding Author: fero@uni-mb.si

Tel: +386-2-220-7331, Fax: +386-2-220-7331, University of Maribor

* Faculty of Electrical Engineering and Computer Science, University of Maribor, Slovenia as effective members of teams requiring strong communication and problem-solving skills. However, it is commonly believed that today's engineering graduates lack these skills and have difficulty applying their fundamental knowledge to practical problems.

Recently, many authors have reported their experiences of using more learner-centered teaching approaches, such as problem-based or project-based learning (PBL), instead of using lecture-based teaching methods, when teaching undergraduate engineering [2]-[7]. Whilst in [2], problem based learning focuses on the dynamic modeling of higher-order switching converter, in [3] the learning process focuses on the system-level behavior model-simulation approach for basic switching converters, in order to enhance the students' learning outcomes. On the other hand, in [4]-[6], authors describe project-based learning approaches that involve design and construction practice. As discussed in [7], the PBL approach offers a number of advantages, amongst which are the ease of controlling the learning process, and the possibility of making rapid changes to the power electronics curriculum.

Although only limited research has been carried out on the beneficial effects of PBL regarding engineering students' learning, it is generally accepted that it enables future engineers to develop their problem-solving skills and, consequently, provides them with the abilities to participate as active and effective members of the global society. Some authors [4], [8] have reported that PBL students score slightly less on factual knowledge, but they retain more of the acquired knowledge, since this knowledge is grounded on context. 
The authors also argued that PBL students develop more conceptual knowledge; hence they are able to better recall their knowledge.

Teaching students through PBL is based on a philosophy that students learn fundamental laws and their applications most effectively through design practices, thus resulting in demonstrated success [8]. Through such practices, students learn that understanding the fundamentals and paying attention to details, are essential requirements for success in engineering. They also become familiar with the science/art of the iterative design process. A strong foundation, consisting of a deep understanding regarding the fundamentals of engineering, and the ability to deal with details, must be provided to students in order to prepare them for advanced courses as well as for the challenges of a highly- competitive industrial world.

From the student point of view, PBL is learner-centered and intrinsically motivating, encouraging collaboration and cooperative learning, that requires students to produce a product, presentation, or performance, by allowing students to make incremental and continual improvements to their product, presentation, or performance. It is designed so that students are actively engaged in 'doing things' rather than in 'learning about' something, and is challenging because it focuses on higher-order skills. Although some students prefer the traditional lectures [8] and feel themselves comfortable learning it because they find themselves more familiar with it, they also underline the importance of PBL in allowing them to apply concepts, and develop their problem solving abilities.

Based on these reported observations, and by taking into account our experiences from previous years, we decided to apply certain traditional lectures in combination with a PBLbased design-project task, as a pedagogical method within a Power Electronics Course. The results from a comprehensively conducted survey at the end of the term, together with their final exam scores, confirmed the suitability and efficiency of our teaching approach. The higher costs associated with investing in material resources and facilities, can be seen as a main drawback of the proposed teaching approach.

The whole project design task is based on ideas from CDIO (Conceive, Design, Implement, Operate), where students are encouraged to consider the whole system's process in order to obtain 'hands-on' experience. According to the basic CDIO premise that 'hands-on' experience is a vital foundation, based on theory and science [10], [11], engineering teaching should be arranged in the following steps: Conceive - students formulate the given task into what needs to be performed in order to fulfill the assignment, Design - students make adequate design/calculations, Implement - based on design, the derived construction is practically implemented, and Operate - the completed construction is analyzed and evaluated.

This paper is organized as follows. Section 2 introduces the design project's task specifications and procedure using basic boost converter calculations and inductor-design procedure. Section 3 presents the magnetic component's final design and a brief analysis of the results. Learning achievements using the PBL approach are evaluated in Section 4, and Section 5 concludes this paper.

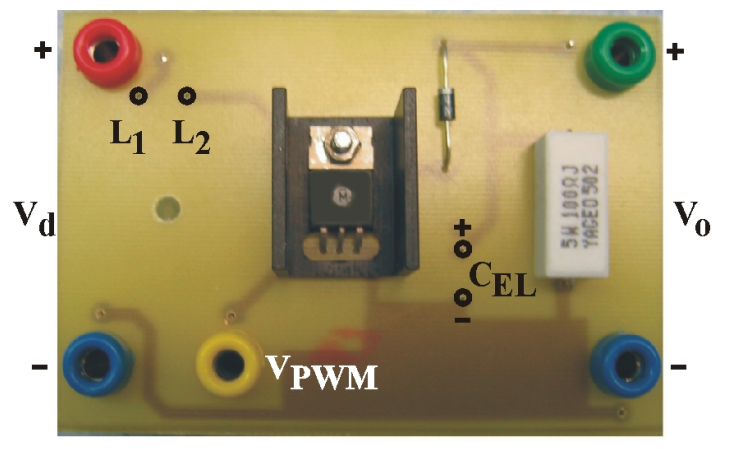

Fig. 1. Boost converter test board layout.

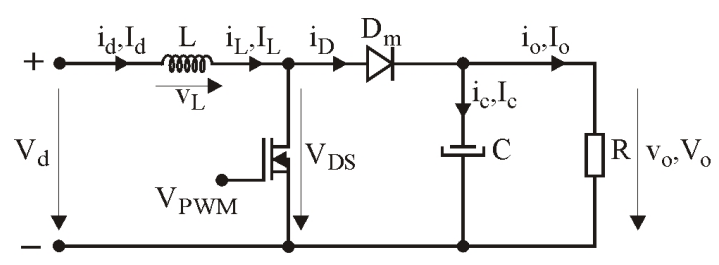

Fig. 2. Boost converter circuit.

\section{Design Project Task Specifications}

The design-project task has to be selected very carefully, so that the students gain a meaningful experience. The designproject task can be considered as suitable if a) it is relevant to the course material, b) the design has been completely workedout beforehand by the instructor, c) it can be performed by students within a relatively short period of time, and d) a prototype can be built.

The design requirements should be specified unambiguously, although they are seldom unambiguous in the professional world, where it is left to the engineer to work out the required details. The following specifications were given to our students: using a boost converter test board layout, as shown in Fig. 1, for building the converter using the following data: a) input voltage $V_{d}=5 \mathrm{~V}$, b) output-voltage $V_{o}=15 \mathrm{~V}$, c) switching-frequency $f_{s}=25 \mathrm{kHz}, \mathrm{d}$ ) minimal load $R=100 \Omega$, e) maximum allowed inductor current ripple $\Delta I_{L}=0.2 \mathrm{~A}$, and f) maximum allowed output voltage ripple $\Delta V_{o}=40 \mathrm{mV}$. An additional requirement was that the converter had to operate within continuous conduction mode. In order to fulfill the given specifications, the students were required to calculate the necessary duty cycle and the main boost converter circuit's parameters, as were the output capacitor $C$, and the main inductor $L$ (see Fig. 2). Additionally, they were also required to design and build the inductor $L$, in order to meet the project's goals. When the students had the opportunity to perform practical work using the theoretical material they had been taught, their understanding of the subject increased.

When applying of boost converter, as shown in Fig. 2, where the operation of a continuous conduction mode is required, the inductance's value $L$ is usually chosen, such that the inductor current's ripple peak-magnitude is a prescribed fractional value of the full-load inductor current's dc component. Based on the calculated inductance value $L$, students had to design the inductor using the procedure described in the following sections. 


\section{A. Design project task procedure}

During the initial phase of the project, the students had to become familiar with the boost converter test-board's layout, and its circuit. At this stage it was important that the relevant fundamental laws were discussed in class, in order to prepare the students for the design project. When the initial phase had been completed, the design project task could be done over the following steps.

\section{B. Basic boost converter calculations}

The basic calculations were based on the assumption that the students were dealing with an ideal boost converter [11]. From the given converter input and output voltage specifications, the required duty cycle $\Delta_{p}$ could be calculated as:

$$
\Delta_{p}=\frac{V_{o}-V_{d}}{V_{o}} .
$$

And converter output power $P_{o}$, output current $I_{o}$ and input current $I_{d}$ as:

$$
\begin{gathered}
P_{o}=\frac{V_{o}^{2}}{R}, \\
I_{o}=\frac{V_{o}}{R}, \\
I_{d}=\frac{I_{o}}{1-\Delta_{p}} .
\end{gathered}
$$

Now the necessary inductance $L$ and capacitance $C$ can be calculated as:

$$
\begin{gathered}
L=\frac{V_{d} \Delta_{p}}{\Delta I_{L} f_{s}}, \\
C=\frac{V_{o}}{R} \frac{\Delta_{p}}{\Delta V_{o} f_{s}} .
\end{gathered}
$$

According to the specification that the converter had to operate in continuous conduction mode, it was necessary to verify whether the following condition had been satisfied:

$$
I_{d} \geq \frac{\Delta I_{L}}{2}
$$

If this condition hadn't been fulfilled, then the specification for the inductor current ripple $\Delta I_{L}$ should be corrected to a lower value that would consequently give a larger value for the inductance $L$. Finally, the rated peak-current through inductor could be calculated as:

$$
I_{L, \max }=I_{d}+\frac{\Delta I_{L}}{2} .
$$

When all the basic calculations were done, the students could start building-up the converter. The easier task is to choose an adequate capacitor, with a capacitance value of at least that calculated using (6), and the difficult one is to design the inductor with an inductance value of at least that given by (5).

\section{Inductor design procedure}

In power electronics circuits, inductive components such as inductors and transformers are basic elements. Since they can not be bought off the shelf as capacitors, they have to be dimensioned, designed, and built-up, and for that, a deep understanding of electromagnetic behavior is essential. Many students lacked a deeper understanding of the inductive components' physics, although they had successfully finished the introduction courses in basic electrical engineering.

In the case of inductor design, there are a large number of design parameters to be chosen including: air-gap length, conductor area, number of turns, all of the magnetic core dimensions, and the type of magnetic material with inductance factor $A_{L}$ included.

The inductor design procedures described in literature make use of numerous monograms, and final result is achieved through several iterations. Therefore, the inductor's design presents a formidable optimization problem, and there is a general perception that it is a difficult task, requiring significant experience [12]-[14]. It is particularly difficult to teach inductor design to students at the undergraduate professional level, since they lack the ability to comprehend difficult physical concepts.

Due to the limited supply of magnetic cores, and to simplify the design procedure, the students were given a toroidal magnetic core L30 with the following specifications: inductance factor $A_{L}=2000 \mathrm{nH}$, saturated flux density $B_{\text {sat }}=350 \mathrm{mT}$, magnetic field strength $\mathrm{H}=250 \mathrm{~A} / \mathrm{m}$, core cross-sectional area $A_{c}=115 \mathrm{~mm}^{2}$ and the average length of he magnetic core's path $l_{m}=l_{c}=45 \mathrm{~mm}$. All calculations for the inductor's design could now be performed, as follows.

Firstly, it was necessary to calculate the required number of turns, $N$ based on inductance value $L$ and inductance factor $A_{L}$. For a magnetic core without an air-gap, this could be done as:

$$
N=\sqrt{\frac{L}{A_{L}}} .
$$

During inductor operation, it is important that the core cannot be energized into saturation when the current increases, so the value of the saturation current $I_{s a t 1}$ for the given core, has to be calculated (see Fig. 3). By applying Amper's Law, and taking into account the distribution of flux density $B$, depending on the magnetic field strength $H$ (see Fig. 4), the saturation current was calculated as:

$$
I_{\text {sat } 1}=\frac{B_{\text {sat }} \cdot l_{m}}{N \cdot \mu}=\frac{l_{m} \cdot H}{N}
$$

where $l_{m}$ is the average length of magnetic core path and $\mu$ is the magnetic permeability of the ferromagnetic core.

When the peak value of inductor current $I_{\text {Lmax }}$, denoted in (8), is close to the calculated value of the saturated current $I_{\text {sat } 1}$, as expressed in (10), then it can be assumed that the core would be saturated when the boost converter is operating. Consequently, the amount of the energy stored in the inductor would be lower, which would result in a lower current and lower converter output power. The temperature in the core would increase, as well as core losses, which would result in a decrease in the converter efficiency. 


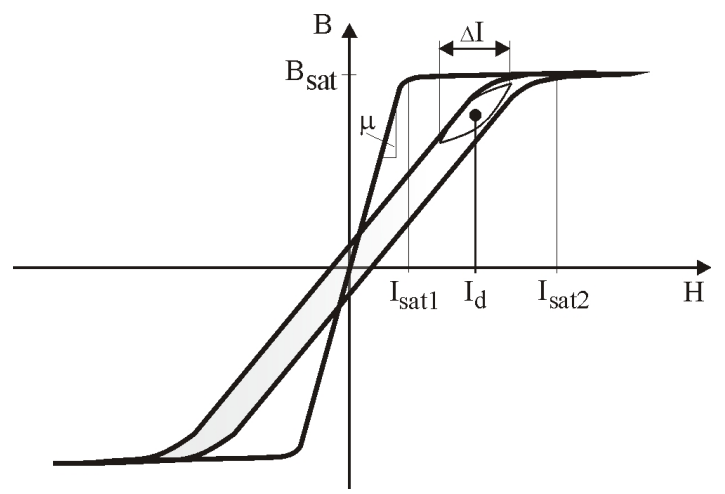

Fig. 3. Magnetic curve of the core with or without a air-gap.

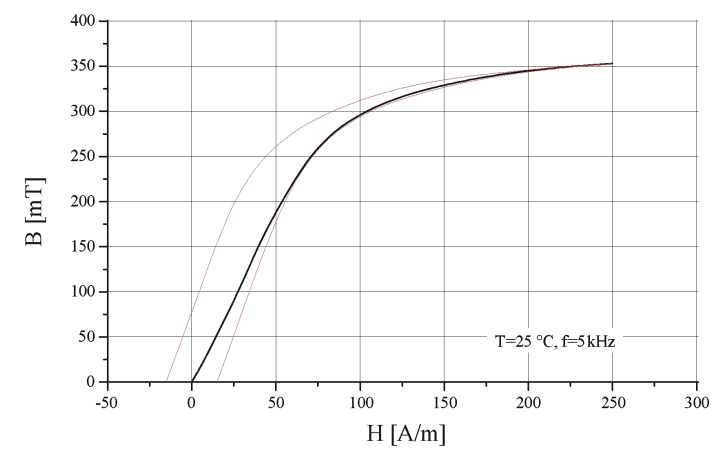

Fig. 4. Distribution of flux-density $B$, depending on the magnetic-field strength H.

So, a decision as to whether the core with the air-gap should be used or not, must be made. If the core with the air-gap is used (see Fig. 5), then the value of the saturated current would be higher (see Fig. 3), and can be calculated as:

$$
I_{\text {sat } 2}=\frac{B_{\text {sat }} \cdot A_{c}}{N}\left(\frac{l_{c}}{\mu \cdot A_{c}}+\frac{l_{g}}{\mu_{0} \cdot A_{c}}\right)=\frac{B_{\text {sat }}}{N}\left(\frac{l_{c} H}{B_{\text {sat }}}+\frac{l_{g}}{\mu_{0}}\right)
$$

where $l_{c}$ is the average length of magnetic core path, $l_{g}$ is the length of air-gap and $\mu_{0}$ is the magnetic permeability in the air. As it is assumed that the core and air-gap have the same cross-sectional areas then, in practice the $\mu>>\mu_{0}$, then the above equation can be simplified to:

$$
I_{\text {sat } 2} \cong \frac{B_{\text {sat }} \cdot l_{g}}{N \cdot \mu_{0}} .
$$

By choosing an appropriate length of air gap $l_{g}$, the value of the saturation current could be set higher than the peak value of the inductor current $I_{L, \max }$, in order to prevent the inductor flux from going into the saturation region during the converter's operation. When the core with the air-gap is employed, the inductance is changed to the next value:

$$
L=\frac{\mu_{0} A_{c} N^{2}}{l_{g}} .
$$

So, finally, the necessary correction for the value of turns numbered $N$, has to be done based on (13), in order to fulfill the requirement for the boost converter inductance $L$ value:

$$
N=\sqrt{\frac{L l_{g}}{\mu_{0} A_{c}}} .
$$

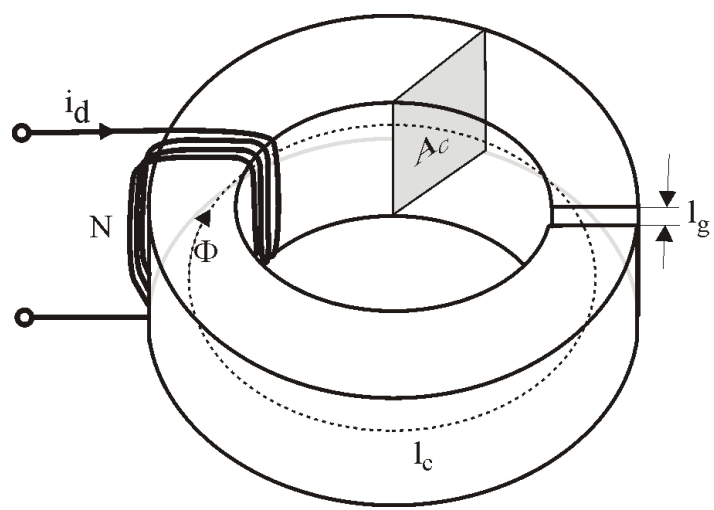

Fig. 5. Structure of the toroidal inductor with air-gap.

With the new value of turns numbered $N$, the value of the saturation current $I_{\text {sat } 2}$ is also changed according to (12), so once more verification as to whether this current is higher than the peak value of the inductor current $I_{L, \max }$, has to be done.

When the above conditions are fulfilled, selecting the diameter of the inductor's copper wire must be done. This selection is based on fact that the maximum value for the current density shouldn't be greater than $J_{\max }=4 \mathrm{~A} / \mathrm{mm}^{2}$. The current density $J_{\max }$ depends on the converter input current $I_{d}$, and the crosssection of the copper wire $S_{C u}$ :

$$
J_{\max } \geq \frac{I_{d}}{S_{C u}} .
$$

So the copper wire's diameter $d_{C u}$ can be determined as:

$$
d_{C u} \geq \sqrt{\frac{4 I_{d}}{\pi J_{\max }}} .
$$

The copper wire diameter from which the inductor will be wound-off should be the first largest ones, with respect to the calculated value in (16).

From the required turns number $N$ and copper wire's diameter, the dc winding-resistance of the inductor, $R_{L}$, can be calculated:

$$
R_{L}=\frac{\rho l_{\text {wire }}}{S_{C u}}=\frac{4 \rho N d_{\text {core }}}{d_{C u}^{2}} .
$$

Where $l_{\text {wire }}$ is the length of the copper wire, $d_{\text {core }}$ is the diameter of the toroidal coil-bobbin, as can be shown in Fig. 6, and $\rho$ is the copper's specific electrical resistivity. It is desirable to obtain the given inductance $L$ with as small a winding-resistance $R_{L}$ as possible, because the winding resistance $R_{L}$ influences the copper losses and, consequently, the boost converter's efficiency. It should be obvious from (17), that the value of the winding-resistance depends on the turns number $N$. When the core with the air-gap is employed, the same inductance $L$ is obtained with a more turns number, compared to the core without an air-gap. As already stated, more turns means more losses, so the decision about using a core with an air-gap has to be carefully made. The resistance $R_{L}$ also reduces the output voltage transfer ratio of the real boost converter:

$$
\frac{V_{o}}{V_{d}}=\frac{R\left(1-\Delta_{p}\right)}{R_{L}+R\left(1-\Delta_{p}\right)^{2}} .
$$



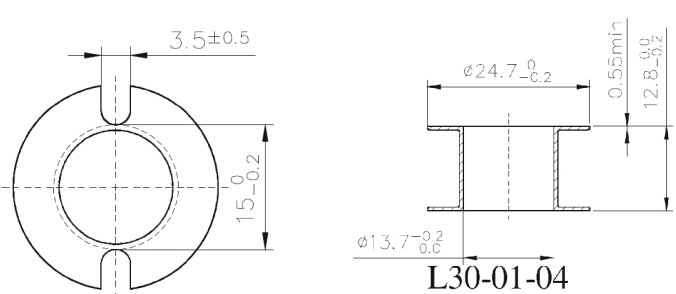

Fig. 6. Dimensions of the toroidal coil-bobbin for the L30.

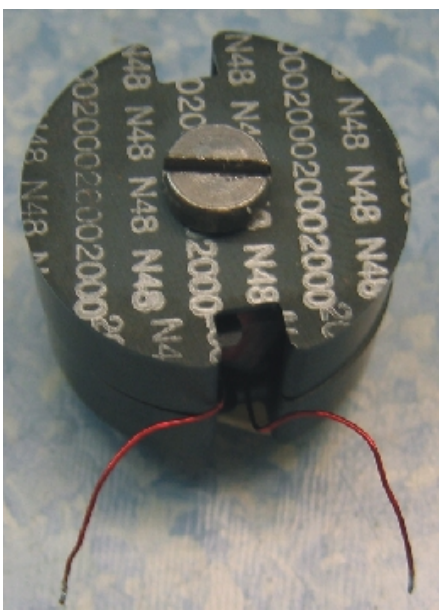

Fig. 7. Inductor built-up by students.

By calculating the derivative of (18) with respect to the duty ratio $\Delta_{p}$, the maximum duty ratio could be found as:

$$
\Delta_{p, \max }=1-\sqrt{\frac{R_{L}}{R}} .
$$

From (19) and (18), the maximum value of the boost converter output voltage can be obtained as:

$$
V_{o, \max }=\frac{V_{d}}{2 \sqrt{\frac{R_{L}}{R}} .}
$$

After all the calculations have been done and the copper wire has been selected, the students can build-up the real inductor. The required turns are carefully wound around the toroidal-coil bobbin (as shown in Fig. 6), and the air-gap is made by using a piece of paper of adequate thickness. The verification, if the required inductance of the inductor $L$ has been obtained, is done by measurement using an LC-Q meter, before the inductor is mounted on the boost converter testboard (see Fig. 7 and 8). At this stage the resistance of the inductor $R_{L}$, should also measured.

\section{ANALYSis AND Evaluation}

When the built inductor $L$, as shown in Fig. 7 , and the chosen capacitor $C$ have been mounted on the boost converter test-board, the students can perform the final analysis and evaluations, if the design-project's task goals have been fully reached.

During the verification process, the students should connect the built boost converter (as shown in Fig. 8) to a $5 \mathrm{~V}$ voltage supply, the duty cycle $\Delta_{p}$ should be adjusted to a value that produces $15 \mathrm{~V}$ voltage at the converter's output, so that the converter operates under nominal operational conditions. Now

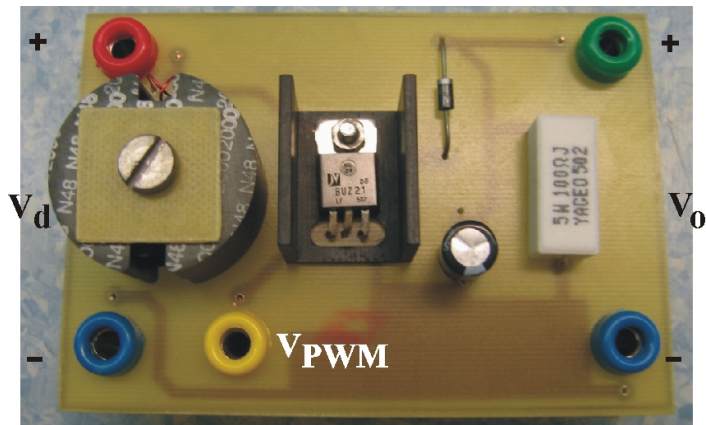

Fig. 8. Boost converter test-board with mounted inductor, and capacitor.

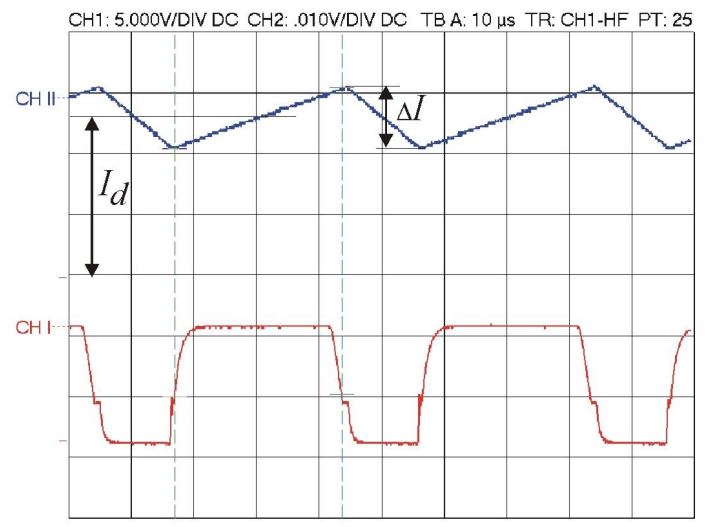

Fig. 9. Waveforms of the driving signal for transistor $V_{P W M}(\mathrm{CH}$ I) and inductor current $I_{L}(\mathrm{CH}$ II, $0.2 \mathrm{~A} / \mathrm{div})$.

they can measure the output voltage ripple $\Delta V_{o}$ as well as the ripple of the inductor current $\Delta I_{L}$.

The waveforms of the inductor current's ripple $\Delta I_{L}$ and the transistor driving signal $V_{P W M}$ are shown in Fig. 9. The current have been measured with a current-probe that provides $10 \mathrm{mV}$ output for each $200 \mathrm{~mA}$ measured. It is evident, that the average input current is around $I_{d}=0.5 \mathrm{~A}$, what is very close to the calculated value in the case of an ideal converter (expected current rate is $I_{d}=0.45 \mathrm{~A}$ ). We should be able to see from Fig 9, that the project's goal for an inductor current ripple of $\Delta I_{L}=0.2 \mathrm{~A}$, has been reached. The maximum output voltage $V_{o, m a s}$ was also measured, compared with the calculated value in (20), and the reasons for the deviations argued about.

\section{Assessment of LeARning AChievements}

Although the PBL approach offers a number of advantages, as reported by several authors, we decided to assess the progress in study achievements within the same group of students. In our case, two similar topics were conducted in the class: the basic course on Industrial Electronics in the $4^{\text {th }}$ semester, and an advanced course on Power Electronics in the $5^{\text {th }}$ semester. In the first case, the students attended within a conventional teaching program: from lectures in the class, homework, mid-term exams, to assistant-guided lab exercises, and the final exam. In the second case, we applied a combination of traditional lectures with the PBL teaching approach within an advanced course on Power Electronics, with emphasis on ideas from the CDIO framework. A comprehensive survey was conducted of the class in the $5^{\text {th }}$ semester using an anonymous questionnaire, and the results within a five 
TABLE I

QUESTIONNAIRE AND RESULTS

\begin{tabular}{|c|c|c|c|c|c|c|}
\hline Question & 1 & 2 & 3 & 4 & 5 & Avg. \\
\hline $\begin{array}{l}\text { 1. How much of the } \\
\text { study up to now has } \\
\text { helped you to consider } \\
\text { being an engineer? }\end{array}$ & 1 & 1 & 12 & 7 & 2 & 3.35 \\
\hline $\begin{array}{l}\text { 2. Do you think that } \\
\text { the PBL has helped } \\
\text { you to better engineer- } \\
\text { ing thought? }\end{array}$ & 0 & 1 & 5 & 14 & 3 & 3.83 \\
\hline $\begin{array}{l}\text { 3. How much did the } \\
\text { PBL encourage and } \\
\text { qualify you for cooper- } \\
\text { ation? }\end{array}$ & 0 & 1 & 7 & 13 & 2 & 3.70 \\
\hline $\begin{array}{l}\text { 4. How much did the } \\
\text { PBL encourage and } \\
\text { qualify you for project } \\
\text { work? }\end{array}$ & 0 & 1 & 8 & 12 & 2 & 3.65 \\
\hline $\begin{array}{l}\text { 5. Please evaluate } \\
\text { the benefits of the } \\
\text { PBL against the } \\
\text { conventional. }\end{array}$ & 0 & 1 & 5 & 13 & 4 & 3.87 \\
\hline $\begin{array}{l}\text { 6. Provide your evalu- } \\
\text { ation of PBL on this } \\
\text { course. }\end{array}$ & 0 & 2 & 6 & 11 & 4 & 3.74 \\
\hline
\end{tabular}

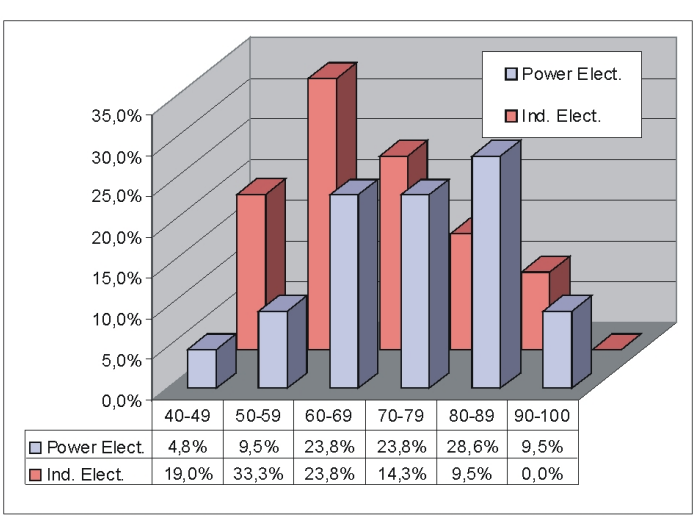

Fig. 10. Comparison of final exam scores with two different teaching approaches.

point scale, are shown in Table I. It is also important to note, that there were more additional questions in this set, where students could express and write down their proposals, new ideas, legitimate critiques, and also possible recommendations.

The percentage comparison of the final grades between the courses in the $4^{\text {th }}$ and $5^{\text {th }}$ semesters is shown in Fig. 10. According to the evaluation results - by using the PBL method in the $5^{\text {th }}$ semester, the students had obtained $10-20 \%$ higher final grades, as a result of better scores in their final exams. This can be seen as a significant improvement with respect to other authors' observations [4], [8]. At the same time, the lower grades had been reduced by similar percentages, as against the $4^{\text {th }}$ semester as well.

The opinions and suggestions that came from the student feedback are very positive with regard to the practical assistance of the laboratory staff. The majority of students felt that the final hands-on layout of the inductor enhanced their understanding of the theoretical background of the electromagnetic theory, and made the course more interesting.

It is also well-known that students who learn the techniques through discussions, quiz, and seek answers to problems, show more interest in the course than those who learn the theory via the traditional instruction approach. The average scores of the mid-term and final examinations also confirm these conclusions. At the end of course, it was found, that majority of the students could now digest those important and difficult topics within their lecture notes, and what the teacher explained during the lectures. A comparison with other universities using conventional education, states that the final yield is much higher using the PBL approach. It is also an encouraging fact that, with this learning approach, we succeeded in also keeping a similar amount of students during the new study semester.

\section{CONCLUSIONS}

This paper focused on teaching students the fundamentals of electromagnetics using the PBL approach, when asked to design an inductor as part of a laboratory assignment on boost converter design. The whole project was prepared according to the CDIO principles, and was well-accepted by students. With respect to the reported experiences in [11], and the fact that we had already worked with these students at the undergraduate professional level, the detailed specification of the tasks during the Conceive (C) phase had already been provided. The students worked in groups of three, and were helped as far as it took for the best of them to carry out their designs successfully. With this teaching approach, the students were asked to apply fundamental laws, and work-out the details to complete design. In our opinion, those students who gained a deep understanding of the fundamental laws can now educate themselves about any given subject. By working on this project design, the students also gained the important experience that calculations are approximations of a real circuit's behavior.

Although the results of this comprehensive survey, and the comparisons of the final exams scores covering two semesters, confirm that the PBL approach upgrades student performance, we found it very important that the basic concepts were taught before PBL was used.

The PBL approach stimulated high-interest amongst all the students and could be seen as a great success. The students enjoyed building their own boost converters, and their rewarding experience will hopefully encourage the students from the next generation to enroll in Power Electronics courses.

\section{REFERENCES}

[1] Z. Jakopovic, V. Sunde, and Z. Bencic, "Undergraduate power electronics laboratory - applying TSMST method," Journal of Power Electronics, Vol. 10, No. 6, pp. 621-627, Nov. 2010.

[2] F. A. Himmelstoss, "On teaching switched mode power supplies - a converter with limited duty cycle," Journal of Power Electronics, Vol. 10, No. 6, pp. 667-672, Nov. 2010.

[3] S. C. Wang, Y. C. Chen, and J. H. Su, "Teaching switching converter design using problem-based learning with simulation of characterization modeling," Journal of Power Electronics, Vol. 10, No. 6, pp. 595-603, Nov. 2010.

[4] D. G. Lamar, P. F. Miaja, M. Arias, A. Rodríguez, M. Rodríguez, and J. Sebastián, "A project-based learning approach to teaching power electronics: difficulties in the application of project-based learning in a subject of switching-mode power supplies," in Proc. EDUCON, pp.717722, Apr. 2010.

[5] F. Martínez, L. C. Herero, and S. de Pablo, "Project-based learning and rubrics in the teaching of power supplies and photovoltaic electricity," IEEE Transaction on Education, Vol. 54, No. 1, pp. 87-96, Feb. 2011. 
[6] R. H. Chu, D. D. C. Lu, and S. Sathiakumar, "Project- based lab teaching for power electronics and drives," IEEE Transactions on Education, Vol. 51, No. 1, pp. 108-113, Feb. 2008.

[7] F. Blaabjerg, "A power electronics and drives curriculum with projectoriented and problem-based learning: a dynamic teaching approach for the future," Journal of Power Electronics, Vol. 2, No. 4, pp. 240-249, Oct. 2002.

[8] A. Yadav, D. Subedi, M. A. Lundeberg, and C.F. Bunting, "Problembased learning: influence on students' learning in an electrical engineering course," Journal of Engineering Education, Vol. 100, No. 2, pp. 253-280, Apr. 2011.

[9] S. M. Miri and R. J. Fu, "A hands-on practical approach to teaching engineering design," IEEE Transaction on Education, Vol. 36, No. 1, pp. 131-136, Feb. 1993.

[10] Worldwide CDIO initiative: A framework for the education of engineers, http://www.cdio.org/index.html, May $31^{\text {st }} 2010$.

[11] L. Max, T. Thiringer, T. M. Undeland, and R. Karlsson, "Power electronics design laboratory exercise for final-year M.Sc. students," IEEE Transaction on Education, Vol. 52, No. 4, pp. 524-531, Nov. 2009.

[12] N. Mohan, T. M. Undeland, and W. P. Robbins, Power Electronics, Devices, Converter, Application and Design, John Willey\&Sons, chap. 30, 1995.

[13] T. M. Undeland, J. Lode, R. Nilssen, W. P. Robbins, and N. Mohan, "A single-pass design method for high-frequency inductors," IEEE Industry Applications Magazine, pp. 44-51, Sept./Oct. 1996.

[14] S. Barmada, R. Rizzo, and L. Sani, "Didactic consideration on magnetic circuits excited by permanent magnets," IEEE Transaction on Education, Vol. 52, No. 4, pp. 532-537, Nov. 2009.

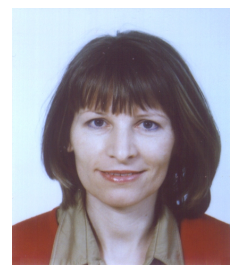

Alenka Hren received the B.S., M.S., and Ph.D. degrees in electrical engineering from the Faculty of electrical engineering and Computer Science, University of Maribor, Slovenia, in 1987, 1990, and 2000, respectively. From 1987 to 1994 she worked as a researcher at the Faculty of Electrical Engineering and Computer Science. Since 1994 she has been working as a teaching assistant at the same institution. In 1990 she spent six months as a visiting researcher at the Imperial College, London, England. She was awarded by the Slovenian Ministry of Science and Technology and ISKRA Holding with the Bedjanic award for master thesis. Her research interests are in the field of power electronics, modelling and control of DC-DC converters, control of electrical drives and estimation techniques as well as introduction of modern power electronics teaching methods. She has published papers in scientific journals and conference proceedings.

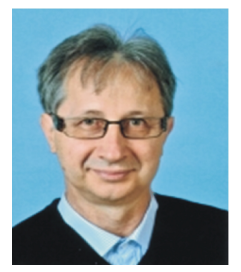

Miro Milanovic (A'88-M'02) received the B.S., M.S., and $\mathrm{Ph} . \mathrm{D}$. degrees in electrical engineering from the University of Maribor, Maribor, Slovenia, in 1978, 1984, and 1987, respectively. From 1978 to 1981, he was a Power Electronics Research Engineer with TSN Company, Maribor. Since 1981, he has been a Faculty Member of the Faculty of Electrical Engineering and Computer Sciences, University of Maribor, where he is currently a full Professor. In 1993, he was a Visiting Scholar at the University of Wisconsin, Madison, and in 1999, he spent two months at the University of Tarragona, Tarragona, Spain, as a Visiting Professor. Currently he has a full professor position at the University of Maribor and he also holds a head position at Institute of robotics. His main research interests include the control of power electronics circuits, unity power factor correction, and switching matrix converters. Dr. Milanovic served as the Vice-President of the Slovenian IEEE section in 2002-2006.

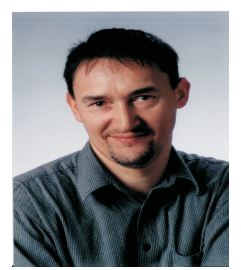

Franc Mihalic received the B.S., M.S. and Ph.D. degrees in electrical engineering from the Faculty of Electrical Engineering and Computer Science, University of Maribor, Slovenia in 1988, 1995 and 2000, respectively. After graduating he worked four months at the electronics factory Elrad in Gornja Radgona, Slovenia. From 1989 to 2002 he was a Teaching Assistant for the power electronics at the Faculty of Electrical Engineering and Computer Science, University of Maribor. In 2002, he spent 3 months at the University of Minho in Guimarães, Portugal as a visiting scholar within the EU Socrates-Erasmus program. From 2002 to 2007 he has been an Assistant Professor and since 2007 an Associate Professor at the

University of Maribor. His research interests include DC-DC converters modeling, high power factor correction techniques, random modulation strategies, signal processing and reduction of electromagnetic interference. He is an IEEE Member in Industrial Electronics-, Power Electronics- and Electromagnetic Compatibility Society, where he serves as a reviewer. 